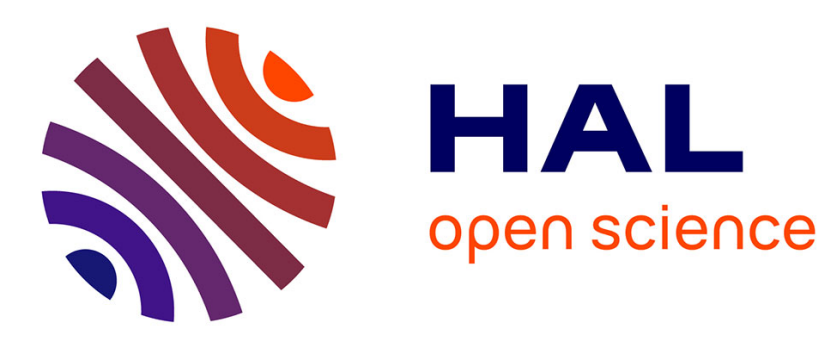

\title{
Picosecond ultrasounds as elasticity probes in neuron-like cells models
}

Alexis Viel, Emmanuel Peronne, Océane Sénépart, Loic Becerra, Claire Legay, Fannie Semprez, Lea Trichet, Thibaud Coradin, Ahmed Hamraoui, Laurent Belliard

\section{To cite this version:}

Alexis Viel, Emmanuel Peronne, Océane Sénépart, Loic Becerra, Claire Legay, et al.. Picosecond ultrasounds as elasticity probes in neuron-like cells models. Applied Physics Letters, 2019, 10.1063/1.5129783 . hal-02376267

\section{HAL Id: hal-02376267 https: / hal.sorbonne-universite.fr/hal-02376267}

Submitted on 22 Nov 2019

HAL is a multi-disciplinary open access archive for the deposit and dissemination of scientific research documents, whether they are published or not. The documents may come from teaching and research institutions in France or abroad, or from public or private research centers.
L'archive ouverte pluridisciplinaire HAL, est destinée au dépôt et à la diffusion de documents scientifiques de niveau recherche, publiés ou non, émanant des établissements d'enseignement et de recherche français ou étrangers, des laboratoires publics ou privés. 


\section{Picosecond ultrasounds as elasticity probes in neuron-like cells models}

Alexis Viel, ${ }^{1}$ Emmanuel Péronne, ${ }^{1}$ Océane Sénépart, ${ }^{2,3,4}$ Loïc Becerra, ${ }^{1}$ Claire Legay, ${ }^{5}$ Fannie Semprez, ${ }^{5}$ Léa

Trichet, ${ }^{2}$ Thibaud Coradin, ${ }^{2}$ Ahmed Hamraoui, ${ }^{2,6}$, a) and Laurent Belliard ${ }^{1}$

${ }^{1)}$ Sorbonne Université, CNRS UMR7588, Institut des Nanosciences de Paris, 4 place Jussieu, 75005 Paris,

France

${ }^{2)}$ Sorbonne Université, CNRS UMR7574, Laboratoire de Chimie de la Matière Condensée de Paris, 4 place Jussieu, 75005 Paris,

France

${ }^{3)}$ Saints-Pères Paris Institute for the Neurosciences, CNRS UMR8003, Université de Paris, Paris Descartes,

Faculté des Sciences Fondamentales et Biomédicales, 45 rue des Saints-Pères, 75006 Paris,

France

${ }^{4)}$ Centre de recherche de l'ECE Paris-Lyon, Immeuble Pollux - 37 quai de Grenelle - CS 71520 - 75015 Paris,

France

${ }^{5)}$ Saints-Pères Paris Institute for the Neurosciences, CNRS UMR 8003, Université de Paris, Paris Descartes,

Faculté des Sciences Fondamentales et Biomédicales, 45 rue des Saints-Pères, 75006 Paris,

France

6) Université de Paris, Paris Descartes, Faculté des Sciences Fondamentales et Biomédicales, 45 rue des Saints-Pères, 75006 Paris,

France

(Dated: November 7, 2019)

We report on elasticity measurements in neuron-like cells using picosecond acoustics pump and probe spectroscopy. The stimulated Brillouin oscillations were mapped in PC12 cells to reveal their internal elastic structure. Thanks to a Pearson correlation coefficient mapping, different areas could be distinguished. The nucleus material shows a bulk modulus equal to $12.9 \mathrm{GPa}$ in the case of dry cell. Attenuation of the Brillouin signature gives access to dynamical longitudinal viscosity equal to $10.6 \mathrm{mPa} \cdot \mathrm{s}$, one order magnitude higher than water. The modulus considerably drops to $2.6 \mathrm{GPa}$ in the most physiologically relevant case of a hydrated cell.

Keywords: Neuronal cell, elasticity, pump and probe spectroscopy.

Cells respond to mechanical signals perceived from the nearest extracellular world ${ }^{1-4}$. For instance, it has been suggested that mechanical constraints prevail over biochemical signaling in the early stage of embryogenesis ${ }^{5}$. Substrate stiffness has also been identified as a key factor driving cell proliferation and differentiation ${ }^{6}$. Both endothelial and smooth muscle cells were shown to proliferate in response to stretching; however, in the case of endothelial cells this response depends on cell-cell adhesion ${ }^{7}$. In the mechanotransduction process, external forces exerted on the cells transit inside them through microscale adhesions domains that serve as anchoring points for the structuration of the cellular cytoskeletal network. This phenomenon allows the cell to sense its surrounding environment and is followed by the activation of fundamental cellular processes involving motility or changes in cell shape ${ }^{8}$. Obviously, how this regulation occurs will depend on the cell type and function. In the case of tumors, the increase in rigidity could be related to various factors, including an increase in the modulus of elasticity of transformed cells due to cellular disturbances. This leads to tumors being generally stiffer than normal tissues 9,10

Perturbation of tissue rigidity is associated with different types of pathology. However, it is sometimes difficult to conclude if this change in stiffness of cells or tissue is the effect or the source of the pathologies ${ }^{11}$. This is why the characterization of the mechanical properties of cells is essential to understand their behavior during mitosis, apoptosis, adhesion,

a)Electronic mail: ahmed.hamraoui@ @orbonne-universite.fr mobility and disease development ${ }^{12-14}$. However, the complexity of the inner cell composition and the intricate meshwork formed by molecular mediators of the transmembrane cell-substrate interactions requires non-invasive techniques to probe and quantify local mechanical properties of cells, including modulus of elasticity, viscoelastic properties, adhesion, and forces created at the single-cell scale. Several recent reviews describe tools used to study cell mechanics ${ }^{15,16}$ and to apply forces on them ${ }^{17}$. The vast majority of conventional methods of measuring the local mechanical properties of cells are based on the use of solid probes, such as AFM, and as a result the measured mechanical properties can strongly depend on the contact/adhesion between the probe and the cell.

In contrast, acoustic waves generated by lasers provide a very adequate tool for probing the mechanical properties of biological cells or tissues in a non-contact, non-invasive configuration. In the optical pump probe technique usually called picosecond acoustics (PA), high frequency acoustic pulses (in the $1-1000 \mathrm{GHz}$ range) can be generated by the pump beam and detected using a delayed probe beam. Since acoustic waves travel several microns per nanosecond, it is possible to study material on a submicron scale with acoustic waves of $10 \mathrm{GHz}$ or more. Such time resolved measurements are known to achieve sound velocity characterization with an accuracy less than $<5 \%$, parameter directly related to the elasticity behavior. In addition, by combining the time and space aspects, it is possible to perform 3D elastic investigations with sub micrometer resolution. To finish, the all-optical approach allows to consider complex environments to address issues related to relevant biological conditions, aqueous media, controlled temperature. For more than 30 years, properties of matter, mainly solid thin metallic films and transparent me- 
dia, have been probed at microscale using $\mathrm{PA}^{18}$. Ten years ago, this technique has been adapted to the study of whole cells ${ }^{19,20}$. Since then, PA experiments has been performed in various configurations to characterize the cell/substrate interactions at the cell scale. For example, the physical properties of the contact between the cell and the substrate has been investigated ${ }^{21,22}$ by characterizing the reflected acoustic pulses. In-depth study of the elastic properties have also been reported in cells for single point measurements ${ }^{23,24}$. Full mapping of a whole cell using Brillouin frequency (BF) has been achieved in-vitro ${ }^{25}$ and more significantly on living cells ${ }^{26-28}$. Indeed, during PA experiments, the cell reflectivity is timedependent and exhibits a decaying oscillating behavior, called the Brillouin oscillations (BO). Since the BO frequency is related to the sound velocity and the decaying time is related to the viscosity, the time domain investigation of $\mathrm{BO}$ signature can be used to carry out an in-depth study of the elastic properties ${ }^{29}$. Recently, a multi parametric elastic mapping in mitotic macrophage cells has been reported ${ }^{30}$, illustrating how the various PA configurations can bring correlative information's to cell investigations.

In this paper, detection of $\mathrm{BO}$ allowed for mapping elastic properties in single neuron-like cells. To our knowledge, this is the first time this technique is used on this type of cells in which the regeneration processes are closely related to cell elasticity.

The elasticity contrasts thus revealed between the nucleus and the cytoskeleton in the reticulate cells also obviously exis in living cells for which the study is more subtle given the very specific conditions necessary for their maintenance. PC12 cells constitute a standard model for adhesion and neuronal differentiation study ${ }^{31-35}$. The frequencies and the lifetimes of the BOs are mapped across the cell using Pearson correlation method. Finally, the influence of hydration, i.e. in more biologically-relevant conditions, on the cell elasticity is investigated.

PC12 cells were routinely maintained following the procedure described in a previously by Hamraoui et al. ${ }^{32-35} \mathrm{PC} 12$ cells cultured on $\mathrm{Ti}-\mathrm{SiO}_{2}$ substrates were fixed using glutaraldehyde/paraformaldehyde (2\% in PBS) at room temperature during $20 \mathrm{~min}$. Then cells were washed twice with PBS for $5 \mathrm{~min}$ and rinsed with deionized water to remove salts.

In order to avoid possible cell overheating induced by the energetic pump beam, $\mathrm{PC} 12$ cells were grown on specific substrates. A $10 \mu m$ thick membrane was obtained by anisotropic etching of silicon and $100 \mathrm{~nm} \mathrm{Ti}$ layer was sputtered on the both sides of the silicon substrate to create an acoustic transducer excited by the pump beam at the bottom side and a cytocompatible top surface for cell adhesion (Fig $1 \mathrm{a}$ ). In this way, working at a modulation frequency of $1.8 \mathrm{MHz}$, the thermal diffusion length in the silicon substrate is much smaller than its thickness, which reduces the rise of the temperature in the PC12 cells deposited on the other top side which is induced by the pump beam on the bottom side. The experimental setup used in this study operating in reflection geometry in an inverted Olympus microscope, has been detailed in previous work ${ }^{36,37}$. A lock-in detection scheme is used to measure the change of sample reflectivity induced by the pump beam.

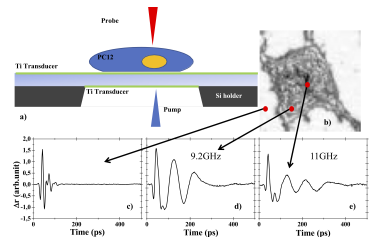

Figure 1. (a) Schematic sample geometry. The thickness of the top silicon device is $10 \mu \mathrm{m}$. The wavelength of the pump and the probe are respectively 400 and $800 \mathrm{~nm}$. (b) Raw optical reflectivity image of a PC12 cell. The red squares indicate the position of the 3 points where differential optical reflectivity is measured (c) outside the cell, (d) and (e) inside the cell. (b) No BO measured on the Ti parts. (d) and (e) : the BO arises within the cell only and show fluctuation from point to point inside the cell.

Both pump and probe beams are focused around $2 \mu \mathrm{m}$ diameter at $1 / e^{2}$. Typical beam powers used in this experiment are $300 \mu \mathrm{W}$ for the pump and $50 \mu \mathrm{W}$ the probe beam.

After an accurate pump and probe alignment, the sample is translated by a piezo-electric stage in order to locate the PC12 cell. Figure $1 \mathrm{~b}$ ) shows an optical image of the cell reflectivity provided by the DC component of the signal after reflection. The acoustic signals b) c) and d) are provided by the AC component of the signal as extracted by the lock-in amplifier. The red dots point to the different locations where the acoustic signal has been recorded. The comparison between the figures $1 \mathrm{c}$ ) and $\mathrm{c}-\mathrm{d}$ ) shows that a decaying oscillation appears when the probe beam is located in the central region of the cell. Named Brillouin oscillations (BO), they arise from the interference between the probe beam reflected at the sample surface and the probe beam reflected by the transient acoustic pulse which propagates into the cell. It is remarkable that the frequency and the lifetime of the oscillation vary with the location of the measurement point, as illustrated in figure 1 $\mathrm{d}$-e). Assuming that the refractive index of the cell is real and constant $n_{\text {cell }}=1.37-1.39^{38}$ through the cell, a fluctuation of elasticity inside the cell can be mapped. Given that the BO frequency is equal to $f_{b}=\frac{2 n v}{\lambda}$, the change of frequency can be correlated to the fluctuation of the sound velocity $v$. Moreover, assuming a constant mass density $\rho=1 \mathrm{~g} . \mathrm{cm}^{-3}$ across the cell, the fluctuation of the dynamical longitudinal viscosity $\mu$ can be evaluated as well, given that the lifetime of the BO is expressed as $\tau=\frac{\rho v^{2}}{4 \pi^{2} f_{b}^{2} \mu} 39$

In order to map the variation of the mechanical properties within the cell, the change of reflectivity has been measured for different pump-probe delays and locations, as sketched in figure 2. By comparing the time dependent signals measured at different pixels like the ones displayed in figure 2, the signals can be evaluated as the sum of two distinct ones. The first signal is the BOs that arise whenever the cell is probed. The second one is the transient feature that occurs repeatedly with decaying amplitude every $31 \mathrm{ps}$. It corresponds to the longitudinal waves emerging at the top free surface, which have been generated by the pump at the bottom interface and have 
propagated back and forth through the titanium layer before propagating through the cell. When the probe beam is not located in the cell, these transient features are the only contribution to the reflectivity signal as illustrated in figure $1 \mathrm{c}$ ). The acoustic echo signal appears to be constant everywhere while the BO part can change drastically from pixel to pixel. Given the temporal signature of the signal between different pixels, it is possible to calculate the cross-correlation between pixels to evaluate the similarity between them and then to sort out the pixels. The Pearson correlation coefficient (Pcc) between one pixel and all the others has been computed for three different pixels (see maps on the right-hand side of figure 2). It allows the clear identification of the regions without (top map) or with cells. Moreover, the Pcc maps of the pixels chosen within the cell shed light on inner cellular structures associated to different $\mathrm{BO}$ when comparing the middle and bottom Pcc maps.

In order to confirm the existence of inner cell acoustic features, we have performed a least square fit of the BO signal with an exponentially decaying cosine function for all the time traces recorded within the cell. The acoustic echo contribution, averaged over the titanium region, has been subtracted prior to the fitting procedure. Figure 3 (a) displays a typical BO signal recorded within the cell with its corresponding fit curve. The fit parameters are: the exponential decay time $\tau$, the cosine amplitude, the cosine frequency $f_{B}$ and the cosine phase. The occurrence of the fitted $\mathrm{BF} f_{B}$ is plotted in figure 3 (b). The distribution displays a bi-modal shape, which can be fitted with a sum of two Gaussian functions. The fit suggests the presence of different inner structures associated with different Brillouin frequencies.

A close inspection of the BF distribution (see figure 3 (b)) reveals that a fair number of pixels associated to low frequency $\left(f_{B}<9.0 \mathrm{GHz}\right)$ is not well accounted for the Gaussian fit of the frequency distribution. Let us divide the frequency domain in three bands: one band centered at $f_{B}=$ $12.4 \mathrm{GHz}$ and $1.0 \mathrm{GHz}$ wide, another domain centered at $f_{B}=10.45 \mathrm{GHz}$ and $2.9 \mathrm{GHz}$ wide; and a last domain such that $f_{B}<9.0 \mathrm{GHz}$. The cell acoustic properties can now be mapped according to the BF as shown in figure 4 . The inner structures revealed by the Pcc maps are confirmed by the Brillouin frequencies mapping. The high BFs domain centered at $12.4 \mathrm{GHz}$ correlates with the nucleus-like features while the middle frequency domain centered at $10.45 \mathrm{GHz}$ would correspond to the cytoplasm. It is important to emphasize that these structures are not distinguishable in the raw reflectivity image presented in figure $1 \mathrm{~b}$. The nuclei exhibit a higher bulk modulus $B=\rho v^{2}$ than the rest of the cell : $12.9 \mathrm{GPa}$ compared to $9.1 \mathrm{GPa}$ respectively. The presence of three nucleus suggest that the studied object is not a single cell but rather the agglomeration of three $\mathrm{PC} 12$ cells.

The typical signal of each frequency domain (i.e. region of the map) is obtained by averaging the signal over the blue, red and green dots distribution shown in the map. The results is plotted in figure 5 (a). As expected, the pixels located at the periphery are associated on average to a decaying time shorter than the Brillouin oscillation period. Indeed, the Brillouin detection mechanism is not expected to be very efficient on the edges of the cell or on the neurite because the cell thickness becomes comparable or smaller than the acoustic wavelength $(\approx 400 \mathrm{~nm})$. In this case the short lifetimes are not directly related to viscosity but are mainly determined by the thickness of the probed biological material. Further development will be needed to obtain elastic information on specific areas using approaches described by Liu et al. ${ }^{30}$. The BO associated to the nucleus is lasting longer than the $\mathrm{BO}$ associated to the cytoplasm. This trend is detailed in figure 5 (b) which plots the cumulated frequency distribution of the fitted lifetime. Nucleus lifetimes are scattered on the long lifetime part of the distribution (blue bars) while the edge lifetime are scattered on the lower part of the distribution (green bars). The surrounding cytoskeleton liftetimes are lying in between. The dynamical longitudinal viscosity can be estimated: the extracted value for the nucleus is equal to $10.6 \mathrm{mPa} . \mathrm{s}$, much larger than in water $(1 \mathrm{mPa} . \mathrm{s})$, which is in good agreement with viscosity value deduced from the motion of organelles transported by motor proteins within cells using fluorescence microscopy ${ }^{40}$. The surrounding cytoskeleton has a higher viscosity estimated at $14.1 \mathrm{mPa}$.s. The uncertainty on the viscosity values is estimated with at $30 \%$ related to the fluctuation of BO lifetime on the areas of interest.

Although live cells $\mathrm{s}^{25,27}$ have been recently probed, such experiments imply complex set-ups so that most of the studies using PA to probe biological objects have involved fixed dried cells. As an intermediate situation, we probed the cell in an hydrated state.

On figure 6, three signals are shown, $\mathrm{BO}$ in the hydrating liquid and $\mathrm{BO}$ in the cell either hydrated or dried. For all samples, the reflectivity signal has the overall same shape as the one observed previously: an acoustical pulse followed by an oscillation. The frequency of the $\mathrm{BO}$ of water is $5.3 \mathrm{GHz}$ ( i.e. longitudinal sound velocity around $1550 \mathrm{~m} \cdot \mathrm{s}^{-1}$ ), whereas this value is almost twice higher, $10 \mathrm{GHz}$, in the dry cell. When the cell is hydrated, this value drops to $5.6 \mathrm{GHz}$ (i.e. longitudinal sound velocity around $1630 \mathrm{~m} \cdot \mathrm{s}^{-1}$ ), close to the one of water. Assuming that the refractive index of the probed cell does not change with the hydration, such a drop of the value of $\mathrm{BF}$ shows the key role played by the hydrating liquid on the mechanical properties of the cell. The value of the average bulk moduli is found around $2.6 \mathrm{GPa}$ close to that of wate ${ }^{25}$ and smaller than in the dry cell. In addition, from the lifetime of the $\mathrm{BO}$ oscillations estimated at $500 \mathrm{ps}$, i.e. 2 to 3 times greater than for the fixed cells, we can estimate a much lower viscosity for the hydrated cells around $4.2 \mathrm{mPa} \cdot \mathrm{s}$.

In conclusion, a special transducer was designed in order to launch and detect $\mathrm{GHz}$ acoustic waves within the cell using pump probe technique. We demonstrated that pump and probe spectroscopy approach coupled with Pearson correlation is a powerful tool to investigate the inner elastic features in $\mathrm{PC} 12$ neuron like-cells such as bulk modulus and dynamical longitudinal viscosity. Mapping the Brillouin oscillation, allowed us to distinguish areas with different local elastic properties inside the probed biological object. Those areas have been identified as specific parts of the cell, for instance areas exhibiting high stiffness and viscosity were assimilated to the nucleus. In the PC12 case, we report a large bulk modulus 

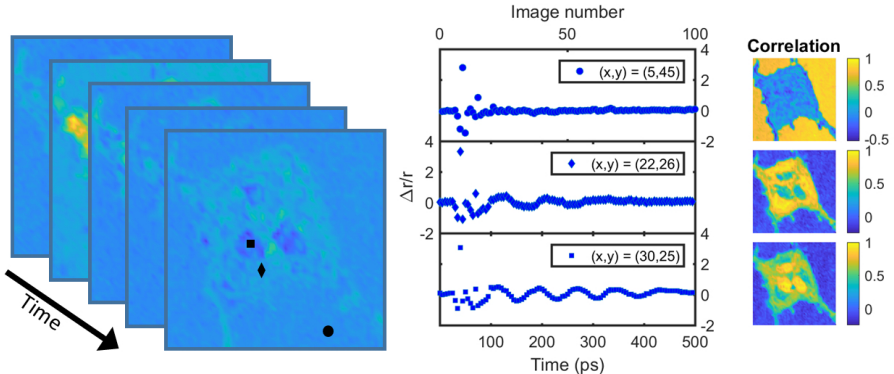

Figure 2. Left: Typical images obtained on a PC12 cell at different pump-probe time delay ( $5 \mathrm{ps}$ time step). Lateral scale $60 \mu m$. Middle: examples of time dependence of the reflectivity for 3 different pixel's coordinates $(x, y)$ extracted from the image sequence (see corresponding symbols). Right : Pearson correlation coefficient maps associated to the three chosen pixels.

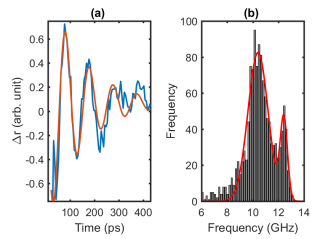

Figure 3. (a) Typical Brillouin oscillation signal obtained inside the cell. The signal is fitted with exponentially decaying cosin function (red line). (b) Frequency distribution of the fitted Brillouin frequencies. The distribution is fitted with a sum of two Gaussian functions (red line).

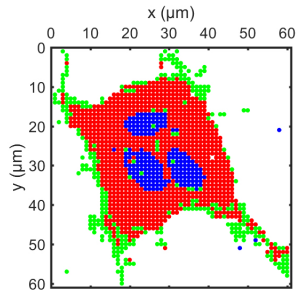

Figure 4. Cell mapping according to the fitted frequency $f_{B}(G H z)$ Blue dots : $11.9<f_{B}<12.9$. Red dots : $9.0<f_{B}<11.9$. Green dots : $f_{B}<9.0$

contrast $(\sim 30 \%)$ between the nucleus and the surrounding cytoskeleton. We also highlight the effect of hydration on the elasticity of cells which opens the door to the study of these systems in living conditions. Combining this approach with

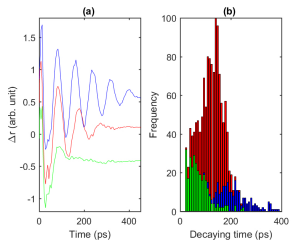

Figure 5. (a) Brillouin oscillation signal averaged over three different spectral ranges. Blue curve : $11.9 \mathrm{GHz}<f_{B}<12.9 \mathrm{GHz}$. Red curve $: 9.0 \mathrm{GHz}<f_{B}<11.9 \mathrm{GHz}$. Green curve : $f_{B}<9.4 \mathrm{GHz}$ and $f_{B}>$ $12.9 \mathrm{GHz}$. (b) Cumulative bar plot of the occurrence of the decaying times corresponding to the three spectral ranges.

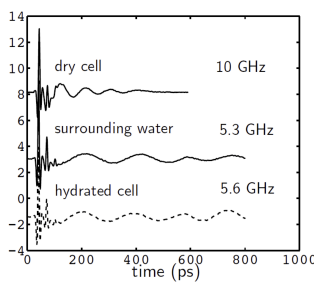

Figure 6. Comparison between time resolved signatures in dry cell (top), aqueous medium ( middle) and hydrated cell ( bottom). The BO frequency in hydrated cell drops significantly towards the value of the solution.

other reported methods on different biological objects, might bring new interesting results in the future.

The authors wish to thank Sorbonne University's Emergence program for its financial support involving INSP. 


\section{REFERENCES}

${ }^{1}$ Ning Wang, Jessica D. Tytell, and Donald E. Ingber. Mechanotransduction at a distance: mechanically coupling the extracellular matrix with the nucleus. Nature Reviews Molecular Cell Biology, 10:75-82, 2009.

${ }^{2}$ Amnon Buxboim, Irena L Ivanovska, and Dennis E Discher. Matrix elasticity, cytoskeletal forces and physics of the nucleus: how deeply do cells 'feel'outside and in? J Cell Sci, 123(3):297-308, 2010.

${ }^{3}$ Adam J Engler, Shamik Sen, H Lee Sweeney, and Dennis E Discher. Matrix elasticity directs stem cell lineage specification. Cell, 126(4):677-689, 2006.

${ }^{4}$ Nathaniel Huebsch, Praveen R. Arany, Angelo S. Mao, Dmitry Shvartsman, Omar A. Ali, Sidi A. Bencherif, José Rivera-Feliciano, and David J. Mooney. Harnessing traction-mediated manipulation of the cell/matrix interface to control stem-cell fate. Nature Materials, 9:518-526, 2010.

${ }^{5}$ D. E. Discher, P. Janmey, and Y. L. Wang. Tissue cells feel and respond to the stiffness of their substrate. Science, 310:1139-1143, 2005.

${ }^{6}$ Rolf Fickentscher, Philipp Struntz, and Matthias Weiss. Mechanical cues in the early embryogenesis of caenorhabditis elegans. Biophys. J, 105:1805$1811,2013$.

${ }^{7}$ Wendy F. Liu, Celeste M. Nelson, John L. Tan, and Christopher S. Chen. Cadherins, rhoa, and rac1 are differentially required for stretch-mediated proliferation in endothelial versus smooth muscle cells. Nature Materials, 101, 2007.

${ }^{8}$ Farhan Chowdhury, Sungsoo Na, Dong Li, Yeh-Chuin Poh, Tetsuya S. Tanaka, Fei Wang, and Ning Wang. Material properties of the cell dictate stress-induced spreading and differentiation in embryonic stem cells. Nature Materials, 9:82-88, 2010.

${ }^{9}$ Michael Beil, Alexandre Micoulet, Götz von Wichert, Stephan Paschke, Paul Walther, M. Bishr Omary, Paul P. Van Veldhoven, Ulrike Gern, Elke Wolff-Hieber, Juliane Eggermann, Johannes Waltenberger, Guido Adler, Joachim Spatz, and Thomas Seufferlein. Sphingosylphosphorylcholine reg ulates keratin network architecture and visco-elastic properties of huma cancer cells. Nature Cell Biology, 5:803-811, 2003.

${ }^{10}$ Jérémie Margueritat, Angélique Virgone-Carlotta, Sylvain Monnier, Hélène Delanoë-Ayari, Hichem C. Mertani, Alice Berthelot, Quentin Martinet, Xavier Dagany, Charlotte Rivière, Jean-Paul Rieu, and Thomas Dehoux. High-frequency mechanical properties of tumors measured by brillouin light scattering. Phys. Rev. Lett., 122:018101, Jan 2019.

${ }^{11} \mathrm{G}$. Bao and S. Suresh. Cell and molecular mechanics of biological materials. Nature Materials, 2:715-725, 2003.

${ }^{12}$ Cheng Zhu, Gang Bao, and Ning Wang. Cell mechanics: Mechanical response, cell adhesion, and molecular deformation. Annual Review of Biomedical Engineering, 2:189-226, 2000.

${ }^{13}$ S. Suresh, J. Spatz, J. P. Mills, A. Micoulet, M. Dao, C. T. Lim, M. Beil, and T. Seufferlein. Connections between single-cell biomechanics and human disease states: gastrointestinal cancer and malaria. Acta Biomaterialia, $1: 15-30,2005$

${ }^{14} \mathrm{~S}$. Suresh. Biomechanics and biophysics of cancer cells. Acta Biomaterialia, 3:413-438, 2007

${ }^{15}$ Deok-Ho Kim, Pak Kin Wong, Jungyul Park, Andre Levchenko, and Yu Sun. Microengineered platforms for cell mechanobiology. Annиal Review of Biomedical Engineering, 11:203-233, 2009.

${ }^{16}$ Robert M. Hochmuth. Micropipette aspiration of living cells. Journal of Biomechanics, 33:15-22, 2000.

${ }^{17}$ Thomas D. Brown. Techniques for mechanical stimulation of cells in vitro: a review. Journal of Biomechanics, 33:3-14, 2000.

${ }^{18} \mathrm{C}$. Thomsen, H. T. Grahn, H. J. Maris, and J. Tauc. Surface generation and detection of phonons by picosecond light pulses. Phys. Rev B, 34:41294138, 1986

${ }^{19}$ Thomas Dehoux, Maroun Abi Ghanem, Omar F. Zouani, Mathieu Ducousso, Nikolay Chigarev, Clément Rossignol, Nicolas Tsapis, MarieChristine Durrieu, and Bertrand Audoin. Probing single-cell mechanic with picosecond ultrasonics. Ultrasonics, 56:160-171, 2015.

${ }^{20}$ C. Rossignol, N. Chigarev, M. Ducousso, B. Audoin, G. Forget, F. Guillemot, and M. C. Durrieu. In vitro picosecond ultrasonics in a single cell Applied Physics Letters, 93:123901, 2008.

${ }^{21}$ T. Dehoux, M. Abi Ghanem, O. F. Zouani, J.-M. Rampnoux, Y. Guillet, S. Dilhaire, M.-C. Durrieu, and B. Audoin. All-optical broadband ultra- sonography of single cells. Scientific reports, 5, 2015.

${ }^{22}$ Maroun Abi Ghanem, Thomas Dehoux, Liwang Liu, Guillaume Le Saux, Laurent Plawinski, Marie-Christine Durrieu, and Bertrand Audoin. Optoacoustic microscopy reveals adhesion mechanics of single cells. Review of Scientific Instruments, 89:014901, 2018.

${ }^{23}$ Atef Gadalla, Thomas Dehoux, and Bertrand Audoin. Transverse mechanical properties of cell walls of single living plant cells probed by lasergenerated acoustic waves. Planta, 239:1129-1137, 2014.

${ }^{24}$ Omar F. Zouani, Thomas Dehoux, Marie-Christine Durrieu, and Bertrand Audoin. Universality of the network-dynamics of the cell nucleus at high frequencies. Soft Matter, 10:8737-8743, 2014

${ }^{25}$ Sorasak Danworaphong, Motonobu Tomoda, Yuki Matsumoto, Osamu Matsuda, Toshiro Ohashi, Hiromu Watanabe, Masafumi Nagayama, Kazutoshi Gohara, Paul H. Otsuka, and Oliver B. Wright. Three-dimensional imaging of biological cells with picosecond ultrasonics. Applied physics letters, 106:163701, 2015.

${ }^{26}$ Fernando Pérez-Cota, Richard J. Smith, Emilia Moradi, Leonel Marques, Kevin F Webb, and Matt Clark. Thin-film optoacoustic transducers for subcellular brillouin oscillation imaging of individual biological cells. Applied Optics, 54:8388, 2015 .

${ }^{27}$ Fernando Pérez-Cota, Richard J. Smith, Emilia Moradi, Leonel Marques, Kevin F. Webb, and Matt Clark. High resolution 3d imaging of living cells with sub-optical wavelength phonons. Scientific Reports, 6, 2016.

${ }^{28}$ Fernando Perez-Cota, Richard J. Smith, Hany M. Elsheikha, and Matt Clark. New insights into the mechanical properties of acanthamoeba castellanii cysts as revealed by phonon microscopy. Biomedical optics express, 10:2399-2408, May 2019.

${ }^{29}$ Vitalyi E. Gusev and Pascal Ruello. Advances in applications of timedomain brillouin scattering for nanoscale imaging. Appl. Phys. Rev., 5:031101, 2018.

${ }^{30}$ Liwang Liu, Laurent Plawinski, Marie-Christine Durrieu, and Bertrand Audoin. Label-free multi-parametric imaging of single cells: dual picosecond optoacoustic microscopy. Journal of biophotonics, page e201900045, 2019.

${ }^{31}$ L. A. Greene and A. S. Tischler. Establishment of a noradrenergic clonal line of rat adrenal pheochromocytoma cells which respond to nerve growth factor. Proc Natl Acad Sci, 73:2424-2428, 1976

${ }^{32}$ Guillaume Lamour, Sylvie Souès, and Ahmed Hamraoui. Interplay between long- and short-range interactions drives neuritogenesis on stiff surfaces. J Biomed Mater Res A, 99(4):598-606, Dec 2011.

${ }^{33}$ Guillaume Lamour, Sylvie Souès, and Ahmed Hamraoui. Substrateinduced pc12 cell differentiation without filopodial, lamellipodial activity or ngf stimulationa. Macromol Biosci, 15(3):364-71, Mar 2015.

${ }^{34}$ Guillaume Lamour, Nathalie Journiac, Sylvie Souès, Stéphanie Bonneau, Pierre Nassoy, and Ahmed Hamraoui. Influence of surface energy distribution on neuritogenesis. Colloids and Surfaces B: Biointerfaces, 72(2):208 $-218,2009$.

${ }^{35}$ Guillaume Lamour, Ali Eftekhari-Bafrooei, Eric Borguet, Sylvie Souès, and Ahmed Hamraoui. Neuronal adhesion and differentiation driven by nanoscale surface free-energy gradients. Biomaterials, 31(14):3762-71, May 2010

${ }^{36}$ T. Bienville, J. F. Robillard, L. Belliard, I. Roch-Jeune, A. Devos, and B. Perrin. Individual and collective vibrational modes of nanostructures studied by picosecond ultrasonics. Ultrasonics, 44:e1289-e1294, 2006.

${ }^{37}$ Cyril Jean, Laurent Belliard, Loïc Becerra, and Bernard Perrin. Backward propagating acoustic waves in single gold nanobeams. Appl. Phys. Lett., $107: 193103,2015$

${ }^{38}$ X. J. Liang, A. Q. Liu, C. S. Lim, T. C. Ayi, and P. H. Yap. Determining refractive index of single living cell using an integrated microchip. Sensors and Actuators A, 133:349-354, 2007.

${ }^{39}$ Geraldine Rohman, Salah Ramtani, Sylvie Changotade, Credson Langueh, Didier Lutomski, Yves Roussigne, Florent Tetard, Frederic Caupin, and Philippe Djemia. Characterization of elastomeric scaffolds developed for tissue engineering applications by compression and nanoindentation tests, mu-Raman and mu-Brillouin spectroscopies. Biomedical Optics Express, 10(4):1649-1659, APR 12019

${ }^{40}$ K. Hayashi, C. G. Pack, M. K. Sato, K. Mouri, K. Kaizu, K. Takahashi, and Y. Okada. Viscosity and drag force involved in organelle transport Investigation of the fluctuation dissipation theorem. Eur. Phys. J. E., 36, 


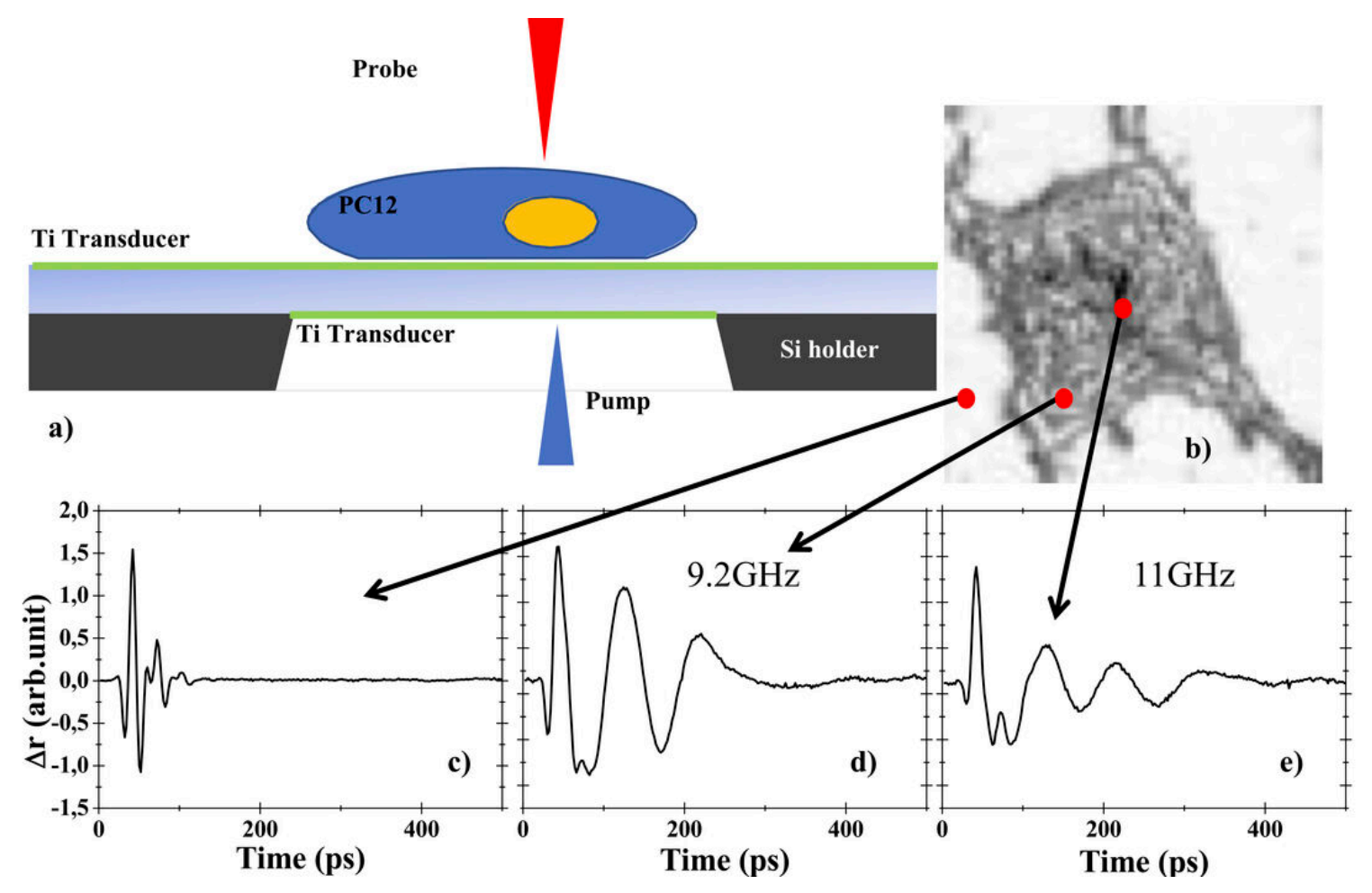



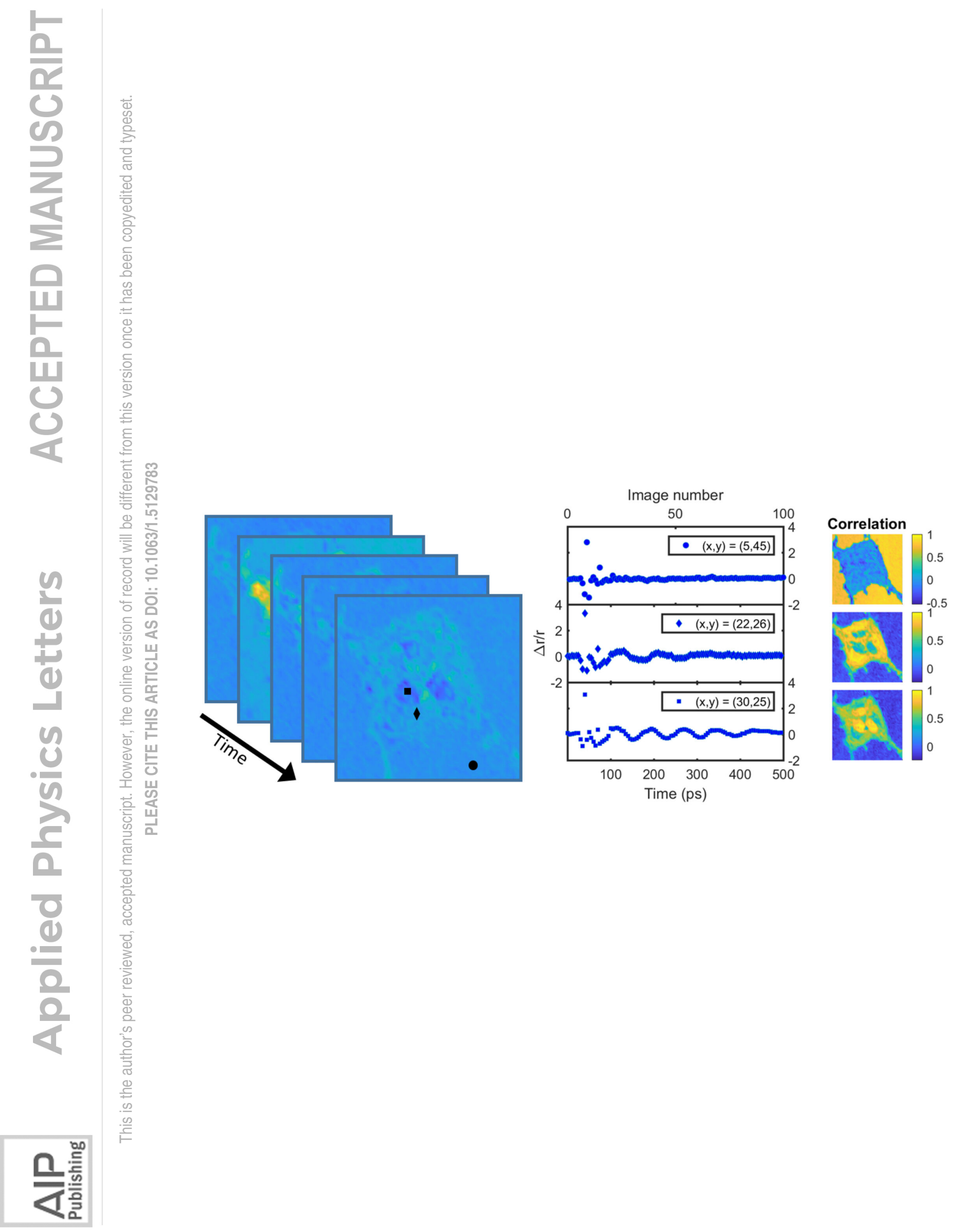
(a)

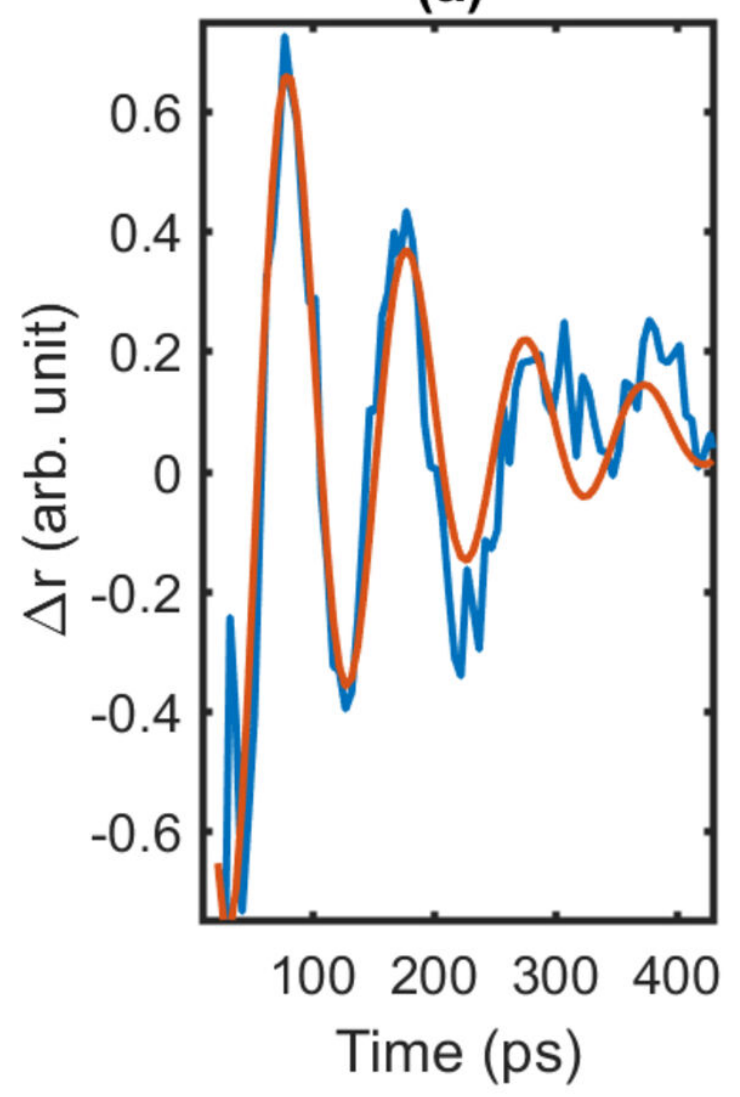

(b)

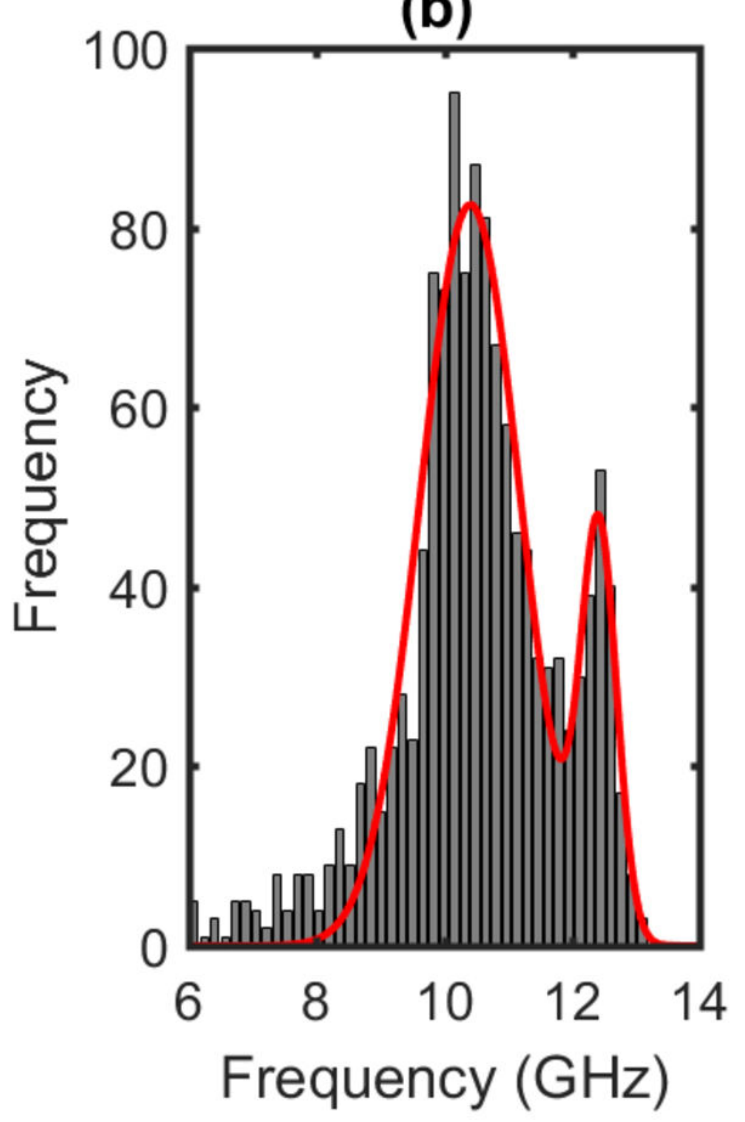




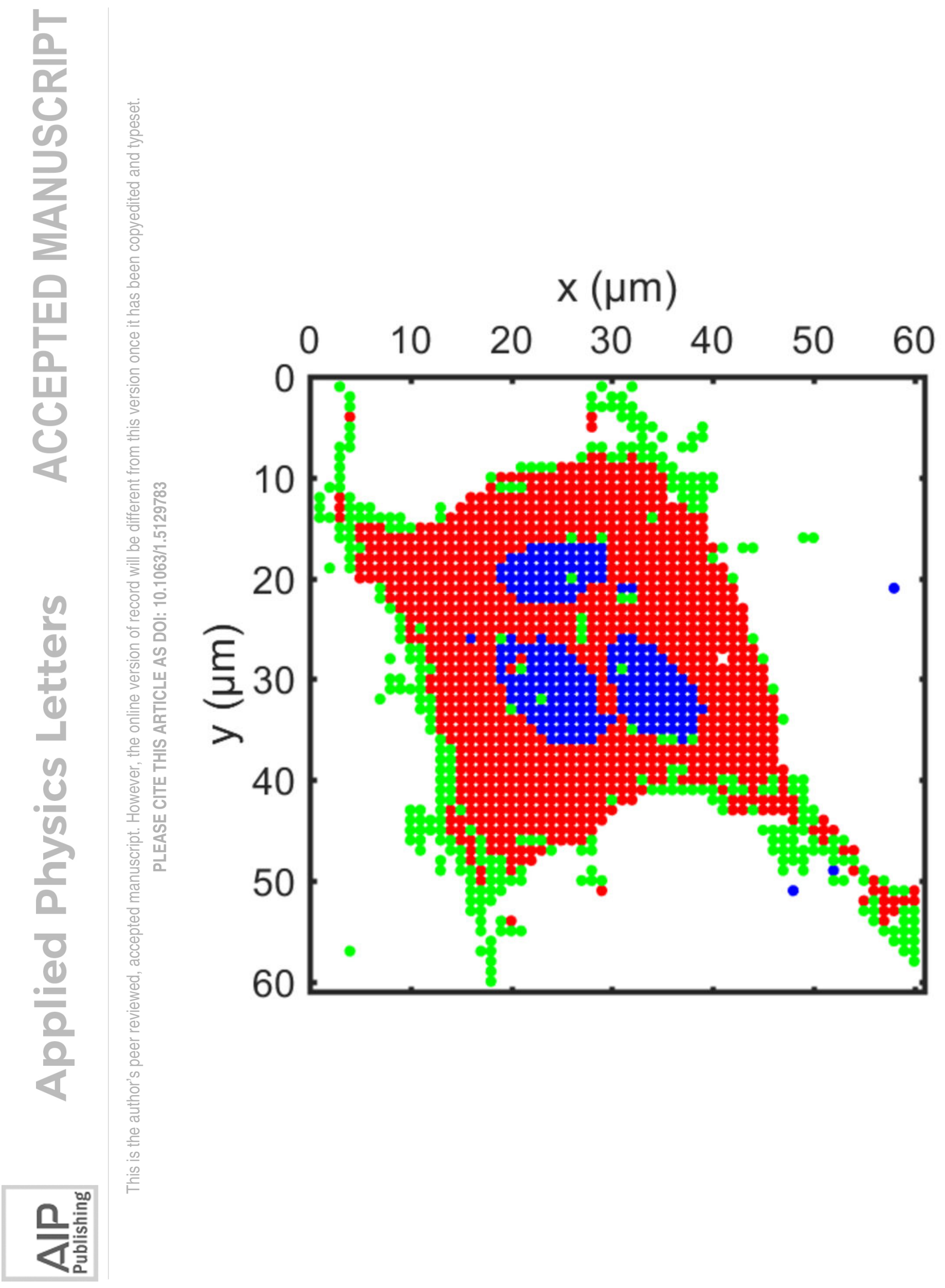


(a)

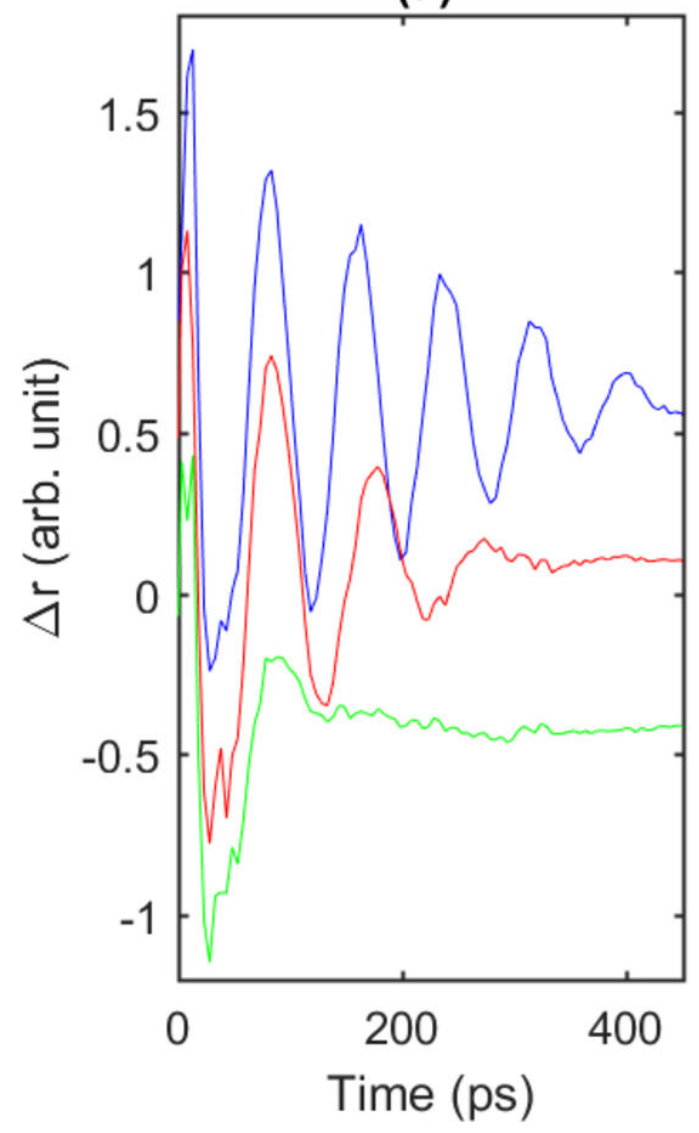

(b)

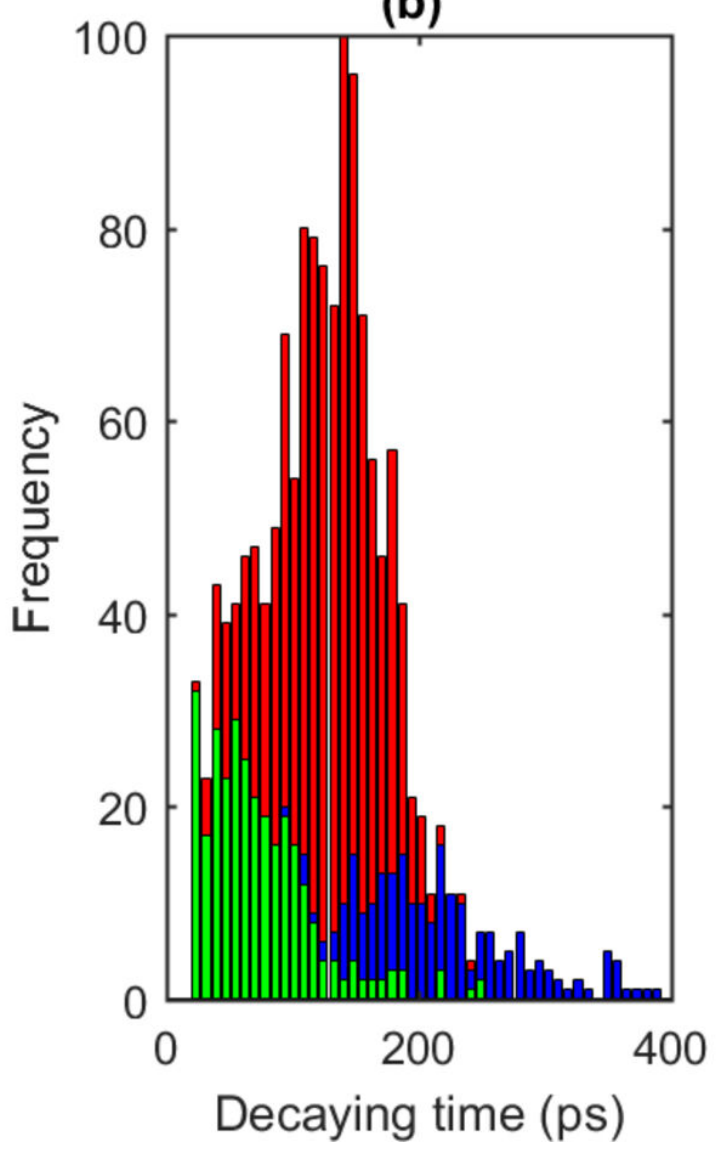




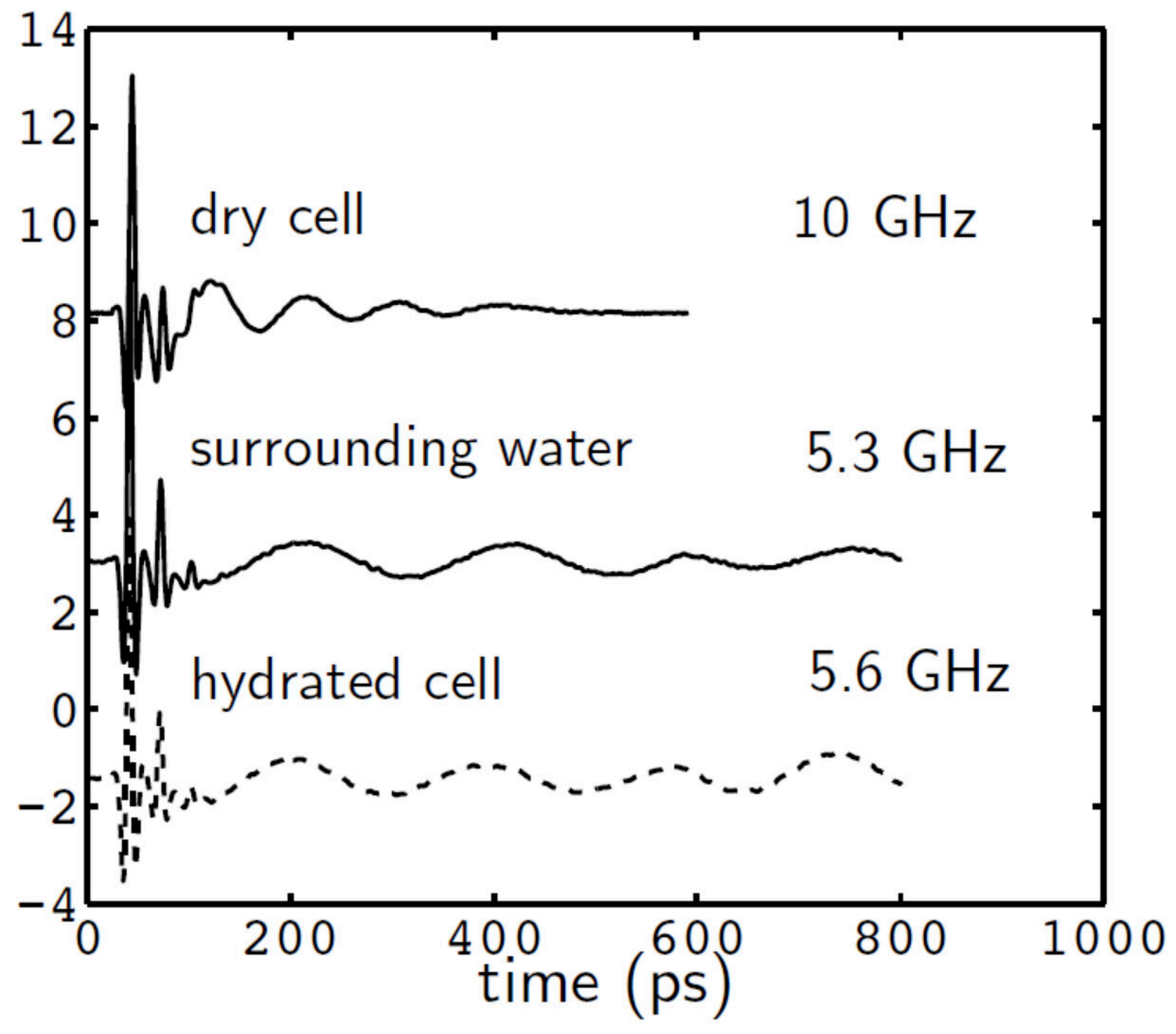

는 